\title{
ANALISIS TINGKAT LOYALITAS KONSUMEN TERHADAP PRODUK ROTI DITOKO ROTTE BAKERY GARUDA SAKTI KECAMATAN TAMPAN KOTA PEKANBARU PROVINSI RIAU
}

\author{
Chezy WM Vermila \\ Staff Pengajar Program Studi Agribisnis \\ Email: chezywmvermila16@gmail.com
}

\begin{abstract}
ABSTRAK
Tujuan penelitian adalah untuk mengetahui karakteristik dan loyalitas konsumen yang membeli Produk Roti Di Toko Rotte Bakery. Metode yang digunakan yaitu metode survei pada toko Rotte Bakery. Hasil yang diperoleh berdasarkan hasil lapangan yaitu untuk karakteristik umur berada pada usia produktif yaitu pada kisaran usia 15-25 tahun sebanyak 66,68\%, tingkat pendidikan responden yaitu pada kisaran 12-15 tahun atau setingkat SMU dan Diploma sebanyak 76,67\%, pendapatan keluarga pada kisaran Rp.1.000.000-Rp.1.500.000 sebanyak 46,67\%, dan pekerjaan dominan responden yaitu Pegawai Swasta sebanyak 36,67\%. Sedangkan untuk hasil analisis loyalitas konsumen belum pada tahap pembeli yang loyal karena piramid loyalitas nilai Switcher buyer masih diatas $50 \%$ dan nilai commited buyer masih sangat kecil yaitu sebesar $26,67 \%$.
\end{abstract}

Kata Kunci : Loyalitas, Konsumen, Roti

\begin{abstract}
The purpose of this study was to determine the characteristics and loyalty of consumers who buy bakery products at Rotte Bakery. The method used is a survey method at the Rotte Bakery. The results obtained are based on the results of the field that is for the characteristics of age at productive age, namely in the age range of $15-25$ years by $66.68 \%$, the level of education of respondents is in the range of 12-15 years or as high as high school and Diploma levels of 76.67\%, income families in the range of Rp.1,000,000 - Rp.1,500,000 were 46,67\%, and the dominant occupation of respondents was Private Employees as much as $36.67 \%$. Whereas the results of the analysis of consumer loyalty are not at the stage of loyal buyers because the pyramid of Switcher buyer loyalty values is still above $50 \%$ and the value of commited buyers is still very small at $26.67 \%$.
\end{abstract}

Keywords: Loyalty, Consumers, Bread

\section{PENDAHULUAN}

Pembangunan ekonomi adalah pertumbuhan ekonomi yang diikuti oleh perubahan dalam struktur dan corak kegiatan ekonomi. Dalam pembangunan ekonomi tingkat pendapatan per kapita terus-menerus meningkat, sedangkan pertumbuhan ekonomi belum tentu diikuti oleh kenaikan pendapatan perkapita. Pertumbuhan menerangkan atau mengukur prestasi dalam perkembangan satu 
perekonomian, tingkat pertumbuhan ekonomi ditentukan oleh pertumbuhan yang sebenarnya barang dan jasa-jasa yang diproduksi sesuatu perekonomian (Sukirno, 2004: 423).

Pembinaan terhadap pengusaha industri kecil juga diarahkan pada masalah harga dan peningkatan kualitas produksi. Salah satu bentuk pembinaan berupa konsultasi peningkatan mutu yang mencakup beberapa aspek dan kegiatan produksi antara lain proses produksi, pemasaran, permodalan, kualitas perhitungan harga pokok serta administrasi pembukuan sederhana.

Tabel 1. Jumlah UMKM di Provinsi Riau

\begin{tabular}{|c|l|c|}
\hline No & $\begin{array}{c}\text { Kabuapaten/ Kota } \\
\text { Provinsi Riau }\end{array}$ & $\begin{array}{c}\text { Jumlah } \\
\text { UMKM }\end{array}$ \\
\hline 1 & Pekanbaru & 68.728 \\
\hline 2 & Kampar & 45.446 \\
\hline 3 & Inhil & 44.891 \\
\hline 4 & Bengkalis & 42.029 \\
\hline 5 & Rohil & 34.036 \\
\hline 6 & Rohul & 27.074 \\
\hline 7 & Inhu & 26.488 \\
\hline 8 & Siak & 22.948 \\
\hline 9 & Kuansing & 21.450 \\
\hline 10 & Dumai & 20.782 \\
\hline 11 & Pelalawan & $\mathbf{3 6 7 . 6 9 6}$ \\
\hline \multicolumn{2}{|c|}{ Jumlah } \\
\hline
\end{tabular}

Disperindag prov.Riau 2018 (data diolah)

Berdasarkan Tabel di atas dapat diketahui bahwa jumlah UMKM di Provinsi Riau dengan jumlah terbanyak yaitu berada di Kota Pekanbaru. Salah satu dari UMKM ini adalah usaha roti yang mana data untuk tiap kecamatan yang ada disajikan pada tabel dibawah ini :

Tabel 2. Jumlah Industri Kecil Menengah (IKM) Roti Dan Kue Kota Pekanbaru 2017

\begin{tabular}{|c|c|c|}
\hline No & Kecamatan & $\begin{array}{c}\text { Jumlah } \\
\text { Industri }\end{array}$ \\
\hline 1 & Payung Sekaki & 4 \\
\hline
\end{tabular}

\begin{tabular}{|c|l|c|}
\hline 2 & Sukajadi & 7 \\
\hline 3 & Marpoyan Damai & 2 \\
\hline 4 & Tampan & 20 \\
\hline 5 & Senapelan & 4 \\
\hline 6 & Bukit Raya & 6 \\
\hline 7 & Sail & 5 \\
\hline 8 & Lima puluh & 8 \\
\hline 9 & Rumbai & 3 \\
\hline 10 & Pekanbaru Kota & 2 \\
\hline 11 & Rumbai Pesisir & 4 \\
\hline \multicolumn{2}{|c|}{ Jumlah } & $\mathbf{6 5}$ \\
\hline
\end{tabular}

Sumber : Disperindag Pekanbaru, 2018

Berdasarkan Tabel 2 dapat dilihat bahwa jumlah industri roti dan kue di Kota Pekanbaru berjumlah 65 usaha pada tahun 2017 yang tersebar hampir diseluruh kecamatan di Kota Pekanbaru. Jumlah industri kue dan roti terbanyak terdapat di Kecamatan Tampan yaitu sebanyak 20 usaha. Selanjutnya di Kecamatan Lima Puluh 8 usaha dan Kecamatan Sukajadi 7 usaha.

Roti dan kue mempunyai pasarnya sendiri dengan jumlah permintaan yang meningkat dari waktu ke waktu di Kota Pekanbaru, roti dan kue digemari berbagai kalangan mulai dari anak-anak hingga lanjut usia. Alasannya, sifat roti dan kue yang enak, praktis dan mengandung gizi yang baik. Kandungan karbohidrat yang ada menjadikan roti dan kue sebagai sumber karbohidrat pengganti nasi. Seiring perkembangan teknologi semakin meningkatkan kesadaran orang akan gizi, sekarang ini roti dan kue tidak hanya dijadikan sebagai penyuplai energi melainkan juga sebagai sumber zat gizi lainya. Berbagai vitamin dan mineral terdapat didalamnya.

Salah satu usaha roti yang sedang populer dikalangan masyarakat yaitu toko Rotte Bakery, yang mana usaha ini berdiri pada tahun 2012 yang mana awalnya usaha ini hanya usaha kecil-kecilan dan berskala rumah 
tangga saja. Namun seiring meningkatnya minat konsumen terhadap produk mereka usaha Rotte ini memperluas jaringan pemasarannya yang berbeda dari penjualan roti pada umumnya. Yang mana mereka mengutamakan kepuasan konsumen dan harga yang lebih terjangkau/murah karena hampir tidak adanya penambahan biaya seperti biaya promosi dan distribusi. Disamping itu, juga terhindar dari resiko barangnya tidak laku karena setiap produk berdasarkan permintaan dari konsumen. Kecamatan Tampan ada 4 cabang Rotte Bakery yaitu : Delima, Garuda Sakti, Soebrantas, dan Kayu Manis.

Berdasarkan penjelasan diataslah penulis tertarik malakukan penelitian dengan judul “ Analisis Tingkat Loyalitas Konsumen Terhadap Produk Roti di Toko Rotte Bakery Garuda Sakti Kecamatan Tampan Kota Pekanbaru Provinsi Riau".

\section{TUJUAN PENELITIAN}

1. Mengetahui karakteristik konsumen yang membeli produk roti di toko Rotte Bakkery.

2. Mengetahui loyalitas konsumen terhadap produk roti di toko Rotte Bakkery.

\section{RUANG LINGKUP PENELITIAN}

Penelitian ini menitik beratkan konsumen yang membeli minimal 3 jenis produk, diantaranya: roti tawar, roti manis, dan donat. Dengan indikator (harga, higienis, aroma, varian rasa, kemasan, dan bentuk/tampilan)

\section{METODE PENELITIAN}

Penelitian ini dilakukan di toko Rotte Bakery cabang Garuda Sakti yang berada di Kecamatan Tampan Kota Pekanbaru Provinsi Riau. Penentuan lokasi dilakukan secara sengaja (porposive) dengan pertimbangan bahwa toko Rotte cabang Garuda Sakti mendapat kunjungan terbanyak oleh konsumen. Penelitian ini dilaksanakan selama 4 bulan yaitu pada bulan Juni 2019 sampai dengan September 2019. Adapun jumlah sampel yang diambil yaitu sebanyak 30 sampel/konsumen.

\section{JENIS DAN SUMBER DATA}

Data yang digunakan dalam penelitian ini berupa data primer dan data sekunder, baik yang bersifat kuantitatif maupun yang bersifat kualitatif. Data primer yaitu data yang diperoleh dari lapangan baik melalui wawancara maupun observasi dan penyebaran kuisioner. Data primer tersebut terdiri dari :

a. Karakteristik konsumen yaitu : umur, pendidikan, pendapatan keluarga, pekerjaan, dan jumlah anggota keluarga.

b. Loyalitas konsumen meliputi : seberapa konsumen tersebut membeli dan mengulang kembali pembelian "Habitual Buyer, Satisfid Buyer, Liking the Brand, Committed Buyer".

Data sekunder terdiri dari : gambaran umum lokasi penelitian, pendidikan, jumlah penduduk, dan mata pencaharian penduduk.

\section{METODE ANALISIS DATA}

Analisis data dilakukan secara kualitatif dan kuantitatif. Data kualitatif disajikan dalam bentuk uraian atau deskripsi, sedangkan data kuantitatif akan disajikan dalam bentuk tabulasi. Perhitungan data dilakukan dengan menggunakan microsoft. Analisis loyalitas yang digunakan yaitu : Switcher Buyer, Habitual Buyer, Satisfied Buyer, Liking The Barnd.

\section{HASIL DAN PEMBAHASAN \\ Gambaran Umum Daerah Penelitian}

Kecamatan Tampan adalah salah satu dari 12 kecamatan yang ada di Kota Pekanbaru. Kecamatan merupakan salah satu kecamatan 
baru sebagai realisasi pelaksanaan Peraturan Pemerintah No. 19 Tahun 1987 Tentang perubahan batas wilayah Kota Madya Daerah Tingkat II Pekanbaru dengan Kabupaten Kampar. Kemudian Kecamatan Tampan ini terbentuk dari gabungan beberapa desa dan kecamatan yang pada awalnya merupakan desa dan Kecamatan dari Kabupaten Kampar yaitu :

a. Desa Simpang Baru dari Kecamatan Kampar

b. Desa Sidomulyo Barat dari Kecamatan Siak Hulu

c. Desa Labuh Baru dari Kecamatan Siak Hulu

d. Desa Tampan dari Kecamatan Siak Hulu

Kecamatan Tampan ini memiliki daerah yang bisa dikatakan cukup luas wilayahnya yaitu lebih kurang $23.788 \mathrm{~km}^{2}$ dan secara monografi Kelurahan ini dibagi menjadi 89 Rukun Tetangga (RT) dan 17 Rukun Warga (RW) serta 6.560 kepala keluarga (KK) dengan jumlah warga 43.550 jiwa. Terdiri dari 19.600 laki-laki dan 23.950 perempuan. Sedangkan mengenai iklim Kecamatan Tampan tidak jauh berbeda dengan iklim daerah lainnya yaitu beriklim tropis (Data Statistik Kantor Camat Tampan, 2017).

\section{Karakteristik Konsumen Roti di Rotte Bakery}

Hasil yang diperoleh pada penelitian ini yang berhubungan dengan karakteristik konsumen yang diamati adalah :

a. Umur

Umur merupakan salah satu faktor penting dalam mempengaruhi keputusan pembelian roti. Berdasarkan survei di lapangan diketahui bahwa konsumen terbanyak untuk pembelian roti berkisar antara 15-20 jiwa, dengan besaran persentase $66,68 \%$. Sedangkan untuk usia 26-35 tahun sebanyak 5 jiwa atau $16,66 \%$. Hal ini menandakan konsumen berada pada usia produktif yang mana konsumen sangat puas terhadap atribut yang disajikan oleh toko Rotte Bakery diantaranya mengenai harga, higienis, aroma, varian rasa, kemasan, dan bentuk.

\section{b. Pendidikan}

Dalam penelitian ini pendidikan formal yang menjadi acuan adalah pendidikan formal yang telah ditempuh konsumen. Tingkat pendidikan akan mempengaruhi nilai-nilai yang dianutnya, cara berfikir, cara pandang bahkan persepsinya terhadap suatu masalah (Sumarwan,2003). Pada penelitian ini terdapat konsumen dengan berbagai latar belakang yang menjadi responden sebagai berikut :

Tabel 3. Data Pendidikan Responden

\begin{tabular}{|l|l|l|}
\hline $\begin{array}{c}\text { Tingkat } \\
\text { Pendidikan }\end{array}$ & Jumlah Jiwa & $\begin{array}{c}\text { Persentase } \\
(\%)\end{array}$ \\
\hline $7-10$ & 0 & 0 \\
\hline $12-15$ & 23 & 76,67 \\
\hline $16-19$ & 7 & 23,33 \\
\hline$>20$ & 0 & 0 \\
\hline Jumlah & 30 & 100 \\
\hline
\end{tabular}

Sumber: data olahan 2019

Berdasarkan Tabel 3 di atas diketahui bahwa konsumen toko Roti Rotte berada pada tingkat SMA dan Diploma sebanyak 76,67 \%. Sedangkan jumlah terbanyak kedua yaitu berada pada tingkat pendidikan Sarjana dan Pasca Sarjana yaitu sebanyak 7 orang atau sama dengan 23,33\%. Hal ini disimpulkan bahwa konsumen dengan tingkat pendidikan tinggi memiliki kecenderungan responsif terhadap informasi baik : harga, higienis, aroma, varian rasa, kemasan, dan bentuk dari suatu barang yang mereka beli atau gunakan, terlebih lagi untuk konsumsi yang mendukung kesehatan keluarga.

c. Pendapatan keluarga

Pendapatan keluarga merupakan indikator penting dalam keputusan pembelian 
terhadap suatu barang. Pendapatan responden pada penelitian ini berkisar pada pendapatan Rp.1.000.000-Rp.1.500.000 sebanyak 14 jiwa atau sama dengan $46,67 \%$, pendapatan Rp.2.000.000-Rp2.500.000 sebanyak 6 jiwa atau sebanyak $20 \%$, dan kisaran pendapatan Rp.3.000.000-Rp.4.000.000 sebanyak 10 jiwa atau sama dengan $33,33 \%$.

d. Pekerjaan

Pekerjaan responden pada penelitian ini bervariasi diantaranya: IRT, PNS, PeGAWAI Swasta, Wiraswasta, Pelajar/Mahasiswa. Jenis pekerjaan konsumen akan mempengaruhi pendapatan yang mereka terima. Pendapatan tersebut kemudian akan mempengaruhi proses keputusan dan pola konsumsi (Sumarwan, 2003).

e. Jumlah Keluaga

Berdasarkan hasil penelitian dilapangan ditemui jenis pekerjaan yang terbanyak yaitu Pegawai swasta sebanyak 11 orang atau $36,67 \%$, kemudian wiraswasta sebanyak 9 orang atau $30 \%$, pelajar sebanyak 8 orang atau 26,66\% dan IRT, serta PNS masingmasing sebanyak 1 orang atau 3,33\%.

Tabel 4. Data Jumlah Keluarga Responden

\begin{tabular}{|l|l|l|}
\hline $\begin{array}{c}\text { Jumlah } \\
\text { Keluarga }\end{array}$ & Jumlah Jiwa & $\begin{array}{c}\text { Persentase } \\
(\%)\end{array}$ \\
\hline $1-2$ & 3 & 10 \\
\hline $3-4$ & 8 & 26,66 \\
\hline $5-6$ & 19 & 63,33 \\
\hline Jumlah & 30 & 100 \\
\hline
\end{tabular}

Berdasarkan Tabel 3 di atas diketahui sebagian besar jumlah keluarga berada pada 5-6 dengan jumlah jiwa 19 orang atau $63,33 \%$, sedangkan urutan berikutnya yaitu 34 anggota keluarga dengan jumlah jiwa sebanyak 8 orang atau $26,66 \%$ dan jumlah anggota keluarga 1-2 sebanyak 3 jiwa atau sama dengan $10 \%$.

\section{ANALISIS LOYALITAS KONSUMEN}

Analisis ini digunakan untuk mengukur tingkat loyalitas konsumen dalam menggunakan/membeli produk roti di toko Rotte Bakery. Menurut Durianto dkk (2004) analisis yang digunakan dalam mengukur tingkat loyalitas yaitu analisis Switcher Buyer, Habitual Buyer, Satisfied Buyer, liking the Brand.

\section{Analisis Switcher Buyer}

Switcher adalah konsumen yang sensitif terhadap perubahan harga, sehingga pada tingkat loyalitas ditempatkan pada urutan paling bawah. Responden yang termasuk kategori ini adalah responden yang menjawab "sering" dan "sangat sering" dalam menjawab pertanyaan "apakah responden berpindah untuk pembelian roti, jika harga naik?

Tabel 4. Perhitungan Analisis Switcher Buyer konsumen Rotte Bakery

\begin{tabular}{|c|c|c|c|c|c|}
\hline \multicolumn{6}{|c|}{ Switcher Buyer } \\
\hline Produk & Jawaban & $\mathrm{X}$ & $\mathrm{F}$ & X.F & $\%$ \\
\hline \multirow{3}{*}{$\begin{array}{l}\text { Roti Tawar, } \\
\text { Roti Manis, } \\
\text { dan Donat }\end{array}$} & Tidak pernah & 1 & 10 & 10 & 33,33 \\
\hline & Sering & 2 & 10 & 20 & 33,33 \\
\hline & Sangat sering & 3 & 10 & 30 & 33,33 \\
\hline \multicolumn{3}{|l|}{ Total } & 30 & 60 & 100 \\
\hline \multicolumn{3}{|l|}{ Rata-rata } & \multicolumn{3}{|c|}{$60 / 30=2$} \\
\hline \multicolumn{3}{|l|}{ Switcher Buyer } & \multicolumn{3}{|c|}{$(10+10) / 30 * 100 \%=66,67$} \\
\hline
\end{tabular}

Sumber: data olahan 2019

Berdasarkan Tabel 4 di atas diketahui bahwa konsumen roti pada toko Rotte Bakery sering berpindah keproduk roti sejenis lainnya. Jika harga yang ditawarkan lebih murah dari harga yang ditawarkan di Toko Rotte Bakery yang biasa dibeli. Hal ini ditunjukkan dengan nilai rata-rata 2 yang dikategorikan sering dengan rentang 1,682,35 . Konsumen yang benar-benar sensitif terhadap harga roti sebanyak 20 responden atau $66,67 \%$.

\section{Analisis Habitual Buyer}

Analisis ini merupakan salah satu analisis deskriptif yang digunakan untuk menggambarkan seberapa besar persentase responden yang memilih Rotte Bakery yang didorong karena faktor kebiasaan. Habitual 
Buyer adalah responden yang dikategorikan sebagai pembeli yang puas dengan produk yang dikonsumsi karena kebiasaan mengkonsumsi. Habitual Buyer dihitung berdasarkan jawaban "setuju" dan "sangat setuju" dengan pertanyaan "apakah responden memilih produk roti karena kebiasaan?”

Tabel 5. Perhitungan Analisis Habitul Buyer Konsumen Toko Rotte Bakery

\begin{tabular}{|l|l|l|l|l|l|}
\hline \multicolumn{5}{|c|}{ Habitual Buyer } \\
\hline Produk & Jawaban & X & F & X. F & $\%$ \\
\hline $\begin{array}{l}\text { Roti } \\
\text { Tawar, } \\
\text { Roti } \\
\begin{array}{l}\text { Manis, } \\
\text { dan } \\
\text { Donat }\end{array}\end{array}$ & $\begin{array}{l}\text { Tidak } \\
\text { setuju }\end{array}$ & 1 & 3 & 3 & 10 \\
\cline { 2 - 6 } & Setuju & 2 & 15 & 30 & 50 \\
\cline { 2 - 6 } & setuju & 3 & 12 & 36 & 40 \\
\hline Total & 30 & 69 & 100 \\
\hline Rata-rata & $69 / 30=2,3$ \\
\hline Switcher Buyer & $(15+12) / 30 * 100 \%=90,67$ \\
\hline
\end{tabular}

Sumber: data diolah 2019

Berdasarkan hasil perhitungan Habitual Buyer diketahui bahwa konsumen roti Rotte Bakery setuju bahwa karena faktor kebiasaan. Hal ini ditunjukkan dengan nilai rata-rata sebesar 2,3 yang dikategorikan setuju dengan rentang 1,68-2,35. Konsumen benar membeli produk roti sebanyak 15 orang atau sebanyak $50 \%$.

\section{Analisis Satisfied Buyer}

Analisis ini menggambarkan seberapa besar persentase responden yang puas, meskipun mungkin saja mereka memindahkan pembeliannya ke merek lain dengan menanggung switching cost yang terkait dengan waktu, uang, atau resiko kinerja yang melekat dengan tindakan mereka beralih merek. Satisfied Buyer adalah responden yang menjawab "puas" dan "sangat puas" dengan pertanyaan "apakah responden puas terhadap produk roti Rotte Bakery?

\begin{tabular}{|l|l|l|l|l|l|}
\hline \multicolumn{2}{|c|}{ Satisfied Buyer } \\
\hline Produk & Jawaban & X & F & X. F & $\%$ \\
\hline Roti & Tidak & 1 & 0 & 0 & 0 \\
\hline
\end{tabular}

\begin{tabular}{|c|c|c|c|c|c|}
\hline \multirow{3}{*}{$\begin{array}{l}\text { Tawar, } \\
\text { Roti } \\
\text { Manis, } \\
\text { dan } \\
\text { Donat }\end{array}$} & puas & & & & \\
\hline & puas & 2 & 18 & 36 & 60 \\
\hline & $\begin{array}{l}\text { Sangat } \\
\text { puas }\end{array}$ & 3 & 12 & 36 & 40 \\
\hline \multicolumn{3}{|l|}{ Total } & 30 & 72 & 100 \\
\hline \multicolumn{3}{|c|}{ Rata-rata } & \multicolumn{3}{|c|}{$72 / 30=2,4$} \\
\hline \multicolumn{3}{|c|}{ Switcher Buyer } & \multicolumn{3}{|c|}{$(18+12) / 30 * 100 \%=100$} \\
\hline
\end{tabular}

Sumber: data diolah 2019

Berdasarkan hasil perhitungan di atas diketahui konsumen roti Rotte Bakery "sangat puas" mengkonsumsi roti, hal ini ditunjukkan dengan nilai rata-rata 2,4 yang berada pada kategori sangat puas yaitu pada rentang 2,363,03 . Konsumen yang benar-benar merasa sangat puas terhadap produk roti sebanyak 30 responden atau sebanyak $100 \%$.

\section{Analisi Liking the Brand}

Analisis ini digunakan untuk menggamnbarkan seberapa besar persentase responden yang membeli roti Rotte Bakery adalah pembeli yang sungguh-sungguh menyukai merek tersebut. Responden yang termasuk liking the brand adalah yang menjawab "suka" dan "sangat suka" dengan pertanyaan "apakah responden benar-benar menyukai merek produk Rotte Bakkery.

\begin{tabular}{|c|c|c|c|c|c|}
\hline \multicolumn{6}{|c|}{ liking the Brand } \\
\hline Produk & Jawaban & $\mathrm{X}$ & $\mathrm{F}$ & $\mathrm{X} . \mathrm{F}$ & $\%$ \\
\hline \multirow{3}{*}{$\begin{array}{l}\text { Roti } \\
\text { Tawar, } \\
\text { Roti } \\
\text { Manis, } \\
\text { dan } \\
\text { Donat }\end{array}$} & $\begin{array}{l}\text { Tidak } \\
\text { suka }\end{array}$ & 1 & 0 & 0 & 0 \\
\hline & suka & 2 & 17 & 34 & 56,67 \\
\hline & $\begin{array}{l}\text { Sangat } \\
\text { suka }\end{array}$ & 3 & 13 & 39 & 43,33 \\
\hline \multicolumn{3}{|l|}{ Total } & 30 & 73 & 100 \\
\hline \multicolumn{3}{|c|}{ Rata-rata } & \multicolumn{3}{|c|}{$73 / 30=2,43$} \\
\hline \multicolumn{3}{|c|}{ Switcher Buyer } & \multicolumn{3}{|c|}{$(16+13) / 30 * 100 \%=100$} \\
\hline
\end{tabular}

Sumber: data diolah 2019

Berdasarkan hasil perhitungan, diperoleh hasil bahwa konsumen roti Rotte Bakery sangat suka mengkonsumsi suatu merek roti. Hal ini ditunjukkan dengan nilai rata-rata sebesar 2,43 yang dikategorikan sangat puas dengan rentang 2,36-3.03. Konsumen yang benar- benar menyukai merek "ROTTE 
BAKERY" sebanyak 30 responden dengan persentase $100 \%$.

\section{KESIMPULAN}

Berdasarkan hasil pembahasan di atas dapat disimpulkan bahwa karakteristik konsumen berada pada usia produktif yaitu pada kisaran usia 15-25 tahun sebanyak $66,68 \%$, tingkat pendidikan responden yaitu pada kisaran 12-15 tahun atau setingkat SMU dan Diploma sebanyak $76,67 \%$, pendapatan keluarga pada kisaran Rp.1.000.000Rp.1.500.000 sebanyak 46,67\%, dan pekerjaan dominan responden yaitu Pegawai Swasta sebanyak $36,67 \%$.

Sedangkan untuk hasil analisis loyalitas konsumen belum pada tahap pembeli yang loyal karena piramid loyalitas nilai Switcher buyer masih diatas $50 \%$ dan nilai commited buyer masih sangat kecil yaitu sebesar $26,67 \%$.

\section{DAFTAR PUSTAKA}

Durianto D, Sugiarto, Sitinjak T. 2004. Strategi Menaklukan Pasar Melalui Riset

Ekuitas dan Perilaku Konsumen. Jakarta:

Gramedia Pustaka Utama.

Sukirno, Sadono. 2004 . Makro Ekonomi:

Teori Pengantar. Jakarta: Raja Grafindo Sejahtera.

Sumarwan, U. 2003. Perilaku Konsumen : Teori dan Penerapnnya dalam Pemasaran. Bogor: Ghalia Indonesia. http//www.Stratford.Gov.uk/files/seealsodocs/ 9370/ customer. Diakses Juli 2019. 